\title{
Mismatch between Arab women's preferences and options offered for treatment of stress urinary incontinence in the United Arab Emirates
}

S. George, ${ }^{1}$ M.J. Hashim, ${ }^{2}$ M.H.S. Al Belooshi, ${ }^{3}$ R.S. Al Hebsi, ${ }^{3}$ A.A. Bloushi, ${ }^{3}$ S.A. Balfaqeeh ${ }^{3}$ and A. Al Midfa ${ }^{3}$

$$
\begin{aligned}
& \text { عدم التطابق بين ما تفضله النساء العربيات والاختيارات المقدمة لهن لمعالجة سَلَس البول الكَرْبي في الإمارات العربية المتحدة }
\end{aligned}
$$

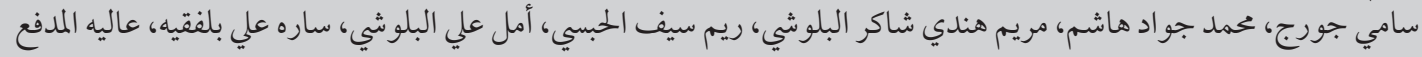

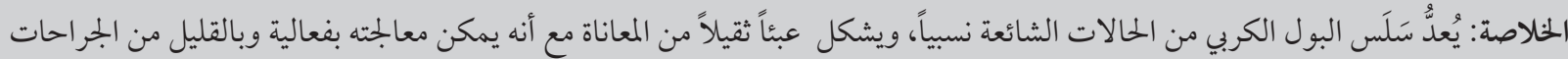

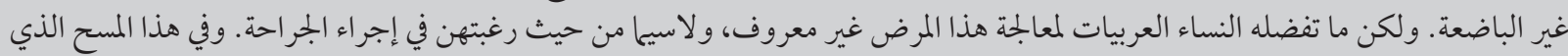

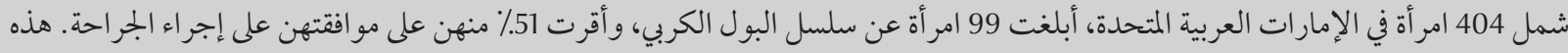

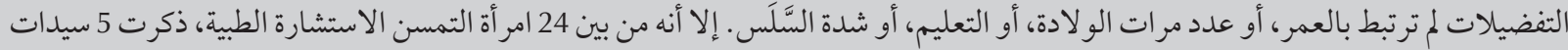

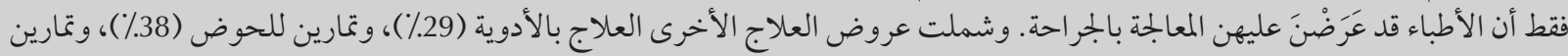

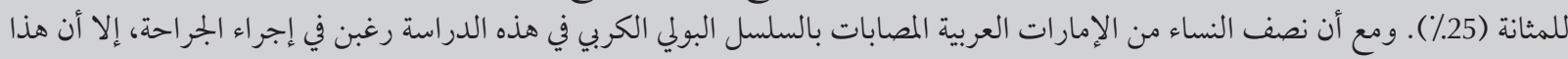

$$
\begin{aligned}
& \text { النوع من المعالجة لم يقدم إليهن على نحو روتيني. نمئ. }
\end{aligned}
$$

ABSTRACT Stress urinary incontinence is a relatively common condition with a high burden of suffering that can be treated effectively with minimally invasive surgery. Treatment preferences for this condition in Arab women are not known, especially in regard to willingness to undergo surgery. In this survey of 404 women across the United Arab Emirates, 99 had self-reported stress urinary incontinence and 51\% of these stated they would undergo surgery. This preference was not related to age, parity, education or severity of incontinence. However, of the 24 women who sought medical advice, only 5 recalled being offered surgical management by their physicians. Other treatments offered included medication (29\%), pelvic exercise (38\%) and bladder training (25\%). Even though half of the Arab Emirati women with stress urinary incontinence in our study were willing to undergo surgery, this treatment is not being offered routinely.

Décalage entre les préférences des femmes arabes et les options thérapeutiques proposées pour traiter l'incontinence urinaire à l'effort aux Émirats arabes unis

RÉSUMÉ L'incontinence urinaire à l'effort est une affection relativement fréquente entraînant une souffrance importante qui peut être traitée efficacement par une intervention chirurgicale minimalement invasive. Les préférences thérapeutiques des femmes arabes affectées restent à élucider, en particulier par rapport à leur volonté de se soumettre à une chirurgie. Dans la présente étude portant sur 404 femmes des Émirats arabes unis, 99 souffraient d'une incontinence urinaire à l'effort autodéclarée et parmi celles-ci, 51 \% affirmaient être volontaires pour choisir la chirurgie. Cette préférence n'était liée ni à l'âge, ni à la parité, ni au niveau d'études, ni à la sévérité de l'incontinence. Toutefois, sur les 24 femmes qui avaient consulté un médecin, seules 5 se sont souvenues avoir été informées par ce dernier de la possibilité d'une prise en charge chirurgicale. Des médicaments (29\%), des exercices du plancher pelvien (38\%) et une rééducation de la vessie (25\%) étaient les autres traitements proposés. La moitié des femmes émiraties de notre étude souffrant d'incontinence urinaire à l'effort étaient volontaires pour la chirurgie, mais ce type de traitement n'a pas été proposé systématiquement.

${ }^{7}$ Department of Obstetrics and Gynaecology; ${ }^{2}$ Department of Family Medicine; ${ }^{3}$ Faculty of Medicine \& Health Sciences, United Arab Emirates University, Al Ain, United Arab Emirates (Correspondence to M.J. Hashim: jhashim@uaeu.ac.ae).

Received: 03/08/11; accepted: 04/10/11 


\section{Introduction}

Although the prevalence of stress urinary incontinence (SUI) and the burden of suffering caused by this condition among women has been studied extensively, the treatment preference of these patients has received minimal attention. It is sometimes assumed that women from less-developed countries and non-Western backgrounds may not be aware that surgical treatment is an option, or may not be willing to have surgery for this condition. Consequently, physicians may not be offering the full range of management options, especially to less-educated or older women of certain ethnic origins.

Recent research in the Arabicspeaking Middle East region has shown that prevalence and morbidity of urinary incontinence is comparable to that in other parts of the world. The prevalence reported in this region is over $20 \%$ in adult women [1].

Arab Muslim women are particularly distressed by SUI as it impacts on their ability to pray on a daily basis. Embarrassment and misconceptions about this condition prevents a large number of women from seeking treatment. A community-based survey in the United Arab Emirates found that $69 \%$ of women did not seek medical advice for urine leakage, leading to debilitating physical, psychological and social burdens [1]. Women's beliefs about treatment options for incontinence have been noted to affect helpseeking behaviour, including the fear of surgery and a perception of lack of effective treatments $[2,3]$.

However, the effectiveness of minimally invasive surgical techniques is fairly well established in urogynaecology trials [4]. A systematic review comparing minimally-invasive synthetic suburethral sling operations with traditional suburethral slings found them to be equally effective (risk ratio 1.03 in 8 trials involving 599 women) [5]. Minimally invasive surgery was associated with shorter operating times and fewer postoperative urinary complications. Furthermore, these operations can be performed as outpatient procedures under local anaesthesia with conscious sedation [6]. The quality of life has been shown to improve with the minimally invasive tension-free vaginal tape procedure at 12 months follow-up, with a cure rate of $87 \%$ [7].Treatment of SUI has advanced significantly in terms of technique, success rate, non-invasiveness and safety [8].

Unfortunately, these remarkable advances in treatment do not appear to have improved the community burden of suffering from SUI. Whether this is because of women's reluctance to have surgery or to not being offered this safe and effective option is unclear. For clinicians and public health professionals, knowledge of women's awareness and preferences for management options are important in discussing treatment choices and for health education campaigns. As treatment preferences and awareness of effective operative management are not known among Arab women, we conducted this cross-sectional survey among Emirati women.

\section{Methods}

We developed a questionnaire and conducted a cross-sectional survey to assess the treatment preferences for SUI among women in the United Arab Emirates. The survey was conducted from June 2009 to March 2010 in 4 cities across the United Arab Emirates, Abu Dhabi, Al Ain, Dubai and Sharjah. The cities were selected on the basis of accessibility. After initial training sessions and a pilot phase, 6 medical students from the United Arab Emirates University administered the questionnaire. A total of 404 women were interviewed in hospitals, primary health care clinics and local communities based on non-random convenience sampling: any potential participants who were present were approached and invited to take part in the survey.

The inclusion criteria were: women age 30 years and above (since SUI is generally related to childbearing and prevalence in younger women is much lower) and United Arab Emirates nationality. Due to the unique needs of our study and the lack of a validated instrument in Arabic, a new questionnaire was developed via multiple iterations and pilot tested in $\mathrm{Al}$ Ain to assess the suitability of the questionnaire. The questions covered demographic data, childbearing and medical conditions as well as specific questions about urine incontinence, treatment options, attitudes and healthcare-seeking behaviour. Most questions were closed-ended with prespecified options.

In this study SUI was defined as "involuntary or accidental leakage of urine with any increase in intra-abdominal pressure such as with coughing, sneezing, laughing, exercise, carrying heavy objects and bending, regardless of its severity or social consequences".

Ethical approval was obtained from Al Ain District Medical Research Ethics Committee at Tawam Hospital, Al Ain and the Faculty of Medicine and Health Sciences, United Arab Emirates University, Al Ain.

\section{Statistical analysis}

Our study was powered to detect a difference of at least $15 \%$ from the preference for surgical treatment of 50\% (minimum sample size 100 subjects; alpha 0.05 ; achieved power $82 \%$; for a 2-tailed, binomial, one-sample calculation). Data analysis was carried out using SPSS, version 18. We used 1-way analysis of variance and nonparametric tests where appropriate. Two-tailed 
significance testing was used with significance level 0.05 .

\section{Results}

Generalizability of the findings can be assessed from the background characteristics of the participants (Table 1). Education level and other demographic variables were used as proxy to assess the representativeness. A range of educational backgrounds was captured in the our sample of 404 women: 37 (9\%) had undertaken postgraduate education, 133 (33\%) had a college or university degree, 119 (30\%) had completed secondary school, 57 (14\%) primary school and 24 women (6\%) had no formal education (data were missing for the rest of the women).

As expected, compared with women who stated they did not have urinary incontinence, women with SUI were statistically significantly older $(P=$ 0.003) (Table 1).

In our sample the prevalence of urinary incontinence was $26.4 \%$ (106/401 women; 3 of the participants were not eligible for inclusion), with a substantial burden of suffering Among the 106 women with incontinence,
99 had SUI as judged by self-reported loss of urine with physical activity: 69 women had leakage with coughing and 11 reported leakage with sexual intercourse (Table 2).

Although 51\% (50/99) of those with SUI indicated that they would undergo surgery, only $20.8 \%(5 / 24)$ of those who had consulted a doctor recalled being offered surgery (Table 3 . Willingness to undergo surgery was not related to age, parity, education or severity of incontinence (Mann-Whitney U-test, $P>0.05$ ).

Only 24 of the 99 women with SUI had sought medical advice (Table 3 ), with the rest feeling: shy or embarrassed (9), 'lazy' (5), UI was not important (20), or UI was normal part of life (44) (data missing for 2 women). Among the 24 women with SUI who did discuss the issue with physicians, $50 \%(12 / 24)$ consulted gynaecologists, $38 \%(9 / 24)$ urologists and $12 \%$ $(3 / 24)$ saw other specialties. Apart from surgical treatment, other options prescribed were: medication $29 \%$ (7/24), pelvic exercise 38\% (9/24) and bladder training $25 \%(6 / 24)$. In some cases, more than 1 treatment was prescribed.

In our study, there was a significant psychosocial burden: $56 \%$ of women with SUI said that the condition interfered with performing their daily prayers and $41 \%$ said it caused them embarrassment (Table 2). Severity of interference with daily living varied from mild 32\% (32/99) to moderate 25\% (25/99) to severe 5\% (5/99) (data missing for 4 women). Coping strategies included frequent changing of underwear (58 women) and wearing pads (23 women) (Table 2).

\section{Discussion}

We found that about half of our sample of Emirati women with SUI were willing to undergo surgery but only about one-fifth of those who consulted a doctor were offered surgical treatment. This is of concern given the high prevalence of this condition and the associated psychosocial morbidity. Our findings run contrary to the misconception that women from a Middle Eastern Arab background are unaware of treatment options or would prefer non-surgical options only. In particular, age and education status do not seem to affect the preference for surgery. These findings have not been reported in previous studies from this region to our knowledge.

\begin{tabular}{|c|c|c|c|}
\hline \multirow[t]{2}{*}{ Characteristic } & $\begin{array}{l}\text { Women with SUI } \\
\qquad(n=99)\end{array}$ & $\begin{array}{l}\text { Women without SUI }{ }^{\mathrm{a}} \\
\qquad(n=305)\end{array}$ & $P$-value ${ }^{b}$ \\
\hline & Mean (SD) & Mean (SD) & \\
\hline Age (years) & $42.5(8.4)$ & $37.8(7.1)$ & 0.003 \\
\hline Weight (kg) & $77.0(17.7)$ & $72.2(15.8)$ & 0.82 \\
\hline $\mathrm{BMI}\left(\mathrm{kg} / \mathrm{m}^{2}\right)$ & $31.1(7.4)$ & $28.7(6.0)$ & 0.20 \\
\hline Level of educationc & $2.3(1.1)$ & $2.4(1.0)$ & 0.62 \\
\hline No. of children & $6.3(3.5)$ & $4.7(2.8)$ & 0.09 \\
\hline No. of vaginal deliveries & $5.7(3.6)$ & $4.3(2.9)$ & 0.20 \\
\hline No. of instrumental deliveries & $0.05(0.2)$ & $0.07(0.3)$ & 0.49 \\
\hline No. of C-sections after trial of labour & $0.13(0.3)$ & $0.15(0.5)$ & 0.19 \\
\hline No. of C-sections without labour & $0.37(1.1)$ & $0.19(0.6)$ & 0.79 \\
\hline
\end{tabular}

ancludes 7 women with non-stress urinary incontinence.

${ }^{b} P$-values for univariate general linear model (1-way analysis of variance) analysing 278 cases, adjusted $R^{2} 0.091$.

'Level of education coded on a scale of: $5=$ postgraduate training to $1=$ no formal education.

$S D=$ standard deviation; $B M I=$ body mass index; of $C$-section = caesarean section. 


\begin{tabular}{lc}
\hline $\begin{array}{l}\text { Table } 2 \text { Burden of suffering in women in the United Arab Emirates aged 30+ years } \\
\text { with stress urinary incontinence }\end{array}$ & $\begin{array}{c}\text { No. of women } \\
(\boldsymbol{n}=\mathbf{9 9})\end{array}$ \\
\hline Issue & 69 \\
Cause for leakage & 11 \\
With cough & 8 \\
With intercourse & 8 \\
With exercise & 2 \\
On standing from a sitting position & \\
With orgasm & 62 \\
Impact on life & 56 \\
Interference with daily life & 41 \\
Interference with prayers & 11 \\
Embarrassment & \\
Noticed by spouse & 58 \\
Coping strategy & 23 \\
Frequent changing of underwear & 13 \\
Wearing perineal pads & 18 \\
Decreased fluid intake & \\
Avoiding physical activity & \\
\hline
\end{tabular}

${ }^{a}$ Self-reported (loss of urine).

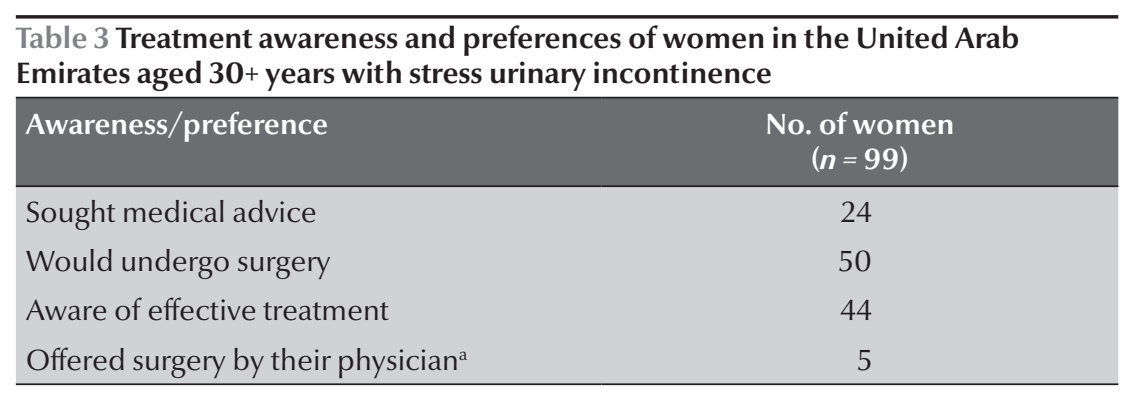

${ }^{a}$ Of those women who had sought medical advice.

Previous research on treatment preferences of women with urinary incontinence elsewhere provides some validation to our findings. During decision making for urinary incontinence, $60 \%$ of women in a Norwegian survey preferred an active role [9]. These women tended to be more educated, single and younger. Knowledge of treatment options was mostly low among immigrant Moroccan and Turkish women in a small qualitative study in the Netherlands [10]. On the other hand, one-third of these women felt that their physician had not taken them seriously, impact on prayers and personal life, and coping mechanisms correspond with previous reports from the region [14] and elsewhere [3]. The reluctance of women to discuss this condition with physicians has been reported in a community survey from London [15] with $32 \%$ of women with urinary incontinence seeking medical care compared with $27 \%$ in our study. The reasons stated by the women in London were strikingly similar to those in the United Arab Emirates, including embarrassment and acceptance as part of aging, despite the differences in culture and society.

The limitations of our study include recall bias, use of a non-validated survey instrument and non-probabilistic sampling.

Further research should assess clinical appropriateness of SUI treatments recommended by physicians in this region and qualitative research about perceptions of women in the United Arab Emirates of treatment options.

\section{Conclusion}

This study shows that Emirati Arab women with SUI are willing to undergo less-invasive surgical treatments but are offered these options relatively infrequently. Based on our findings we recommend that physicians engage women in shared decision-making in SUI treatment, offer the full range of options and avoid generalizing about limiting surgical options to women from certain groups.

\section{Acknowledgement}

We would like to extend our thanks to all the medical students who helped in the collection of these data from the different cities in the United Arab Emirates. 


\section{References}

1. Rizk DE et al. The prevalence and determinants of health careseeking behavior for urinary incontinence in United Arab Emirates women. International Urogynecology Journal and Pelvic Floor Dysfunction, 1999, 10:160-165.

2. Koch LH. Help-seeking behaviors of women with urinary incontinence: an integrative literature review. Journal of Midwifery \& Women's Health, 2006, 51:e39-44.

3. Hägglund D et al. Quality of life and seeking help in women with urinary incontinence. Acta Obstetricia et Gynecologica Scandinavica, 2001, 80:1051-1055.

4. Gilleran JP, Zimmern P. An evidence-based approach to the evaluation and management of stress incontinence in women. Current Opinion in Urology, 2005, 15:236-243.

5. Ogah J, Cody JD, Rogerson L. Minimally invasive synthetic suburethral sling operations for stress urinary incontinence in women. Cochrane Database of Systematic Reviews, 2009, CD006375.

6. Kane AR, Nager CW. Midurethral slings for stress urinary incontinence. Clinical Obstetrics and Gynecology, 2008, 51:124-135.

7. Bakas $\mathrm{P}$ et al. Quality of life in relation to TVT procedure for the treatment of stress urinary incontinence. Acta Obstetricia et Gynecologica Scandinavica, 2006, 85:748-752.

8. Williams ER, Klutke CG. Stress urinary incontinence: the evolution of the sling. Expert Review of Medical Devices, 2008, 5:507-523

9. O'Donnell M, Hunskaar S. Preferences for involvement in treatment decision-making among Norwegian women with urinary incontinence. Acta Obstetricia et Gynecologica Scandinavica, 2007, 86:1370-1376.

10. Van den Muijsenbergh ME, Lagro-Janssen TA. Urinary incontinence in Moroccan and Turkish women: a qualitative study on impact and preferences for treatment. British Journal of General Practice, 2006, 56:945-949.

11. Valpas A et al. A cost-effectiveness analysis of tension-free vaginal tape versus laparoscopic mesh colposuspension for primary female stress incontinence. Acta Obstetricia et Gynecologica Scandinavica, 2006, 85:1485-1490.

12. Ankardal $\mathrm{M}$ et al. Short- and long-term results of the tensionfree vaginal tape procedure in the treatment of female urinary incontinence. Acta Obstetricia et Gynecologica Scandinavica, 2006, 85:986-992.

13. Kuuva N, Nilsson CG. Long-term results of the tension-free vaginal tape operation in an unselected group of 129 stress incontinent women. Acta Obstetricia et Gynecologica Scandinavica, 2006, 85:482-487.

14. El-Azab AS, Mohamed EM, Sabra HI. The prevalence and risk factors of urinary incontinence and its influence on the quality of life among Egyptian women. Neurourology and Urodynamics, 2007, 26:783-788.

15. MacKay K, Hemmett L. Needs assessment of women with urinary incontinence in a district health authority. British Journal of General Practice, 2001, 51:801-804. 